\title{
Protocol for Isolation and Culture of Mouse Hepatocytes (HCs), Kupffer Cells (KCs), and Liver Sinusoidal Endothelial Cells (LSECs) in Analyses of Hepatic Drug Distribution
}

\author{
Kjetil Elvevold, Ingelin Kyrrestad, and Bård Smedsrød
}

\begin{abstract}
Development of the new generation of drugs (e.g., oligo- and polynucleotides administered intravascularly either as free compounds or as nano-formulations) frequently encounters major challenges such as lack of control of targeting and/or delivery. Uncontrolled or unwanted clearance by the liver is a well-known and particularly important hurdle in this respect. Hence, reliable techniques are needed to identify the type(s) of liver cells, receptors, and metabolic mechanisms that are responsible for unwanted clearance of these compounds.

We describe here a method for the isolation and culture of the major cell types from mouse liver: hepatocytes (HCs), Kupffer cells (KCs), and liver sinusoidal endothelial cells (LSECs). The presently described protocol employs perfusion of the liver with a collagenase-based enzyme preparation to effectively transform the intact liver to a single cell suspension. From this initial cell suspension HCs are isolated by specified centrifugation schemes, yielding highly pure HC preparations, and KCs and LSECs are isolated by employing magnetic-activated cell sorting (MACS). The MACS protocol makes use of magnetic microbeads conjugated with specific antibodies that bind unique surface antigens on either KCs or LSECs. In this way the two cell types are specifically and separately pulled out of the initial liver cell suspension by applying a magnetic field, resulting in high purity, yield, and viability of the two cell types, allowing functional studies of the cells.

If the drug compound in question is to be studied with respect to liver cell distribution of intravascularly administered drug compounds the isolated cells can be analyzed directly after isolation. Detailed studies of receptor-ligand interactions and/or dynamics of intracellular metabolism of the compound can be conducted in primary surface cultures of HCs, LSECs, and KCs established by seeding the isolated cells on specified growth substrates.
\end{abstract}

Key words Mouse liver cells, Cell isolation, Kupffer cells, Liver sinusoidal endothelial cells, Hepatocytes, Cell culture, Magnetic-activated cell sorting, MACS

\section{Introduction}

Modern drug treatment modalities frequently include i.v. administration of large molecule compounds or nano-formulations. In either case oligonucleotides may represent the active principle. 
Lack of targeting control is a general challenge when these therapeutics are injected i.v. The main cause of targeting failure is unwanted uptake in liver [1]. Apart from the one noteworthy example of i.v. administered oligonucleotide therapeutics patisiran that successfully targets the major type of liver cells, the hepatocytes (HCs) [2], the general rule is that large molecules/nanoformulations are rapidly cleared from the circulation by specialized scavenger cells lining the wall of the several hundred million capillary-like liver vessels called liver sinusoids. The scavenger cells of the liver sinusoids represent two cell types: the liver sinusoidal endothelial cells (LSECs) and the Kupffer cells (KCs). The KCs are the resident mononuclear phagocytes of the liver and represent by far the largest population of macrophages in the body. These cells are geared to carry out phagocytosis of large blood-borne material ( $>200 \mathrm{~nm}$ ). In contrast the LSECs, representing the great majority of endothelial cells of the liver, are unable to perform phagocytosis under normal conditions, but are among the most active endocytic cells of the body, using clathrin-mediated endocytosis and a set of unique endocytosis receptors [3].

Although the LSECs and KCs make up only $3.3 \%$ and $2.5 \%$ of the total liver volume, the numberwise distribution of same cells is $21 \%$ and $8.5 \%$ [4]. The following anatomical and physiological relationships strongly support the notion that LSECs are optimally geared to carry out extremely efficient blood clearance: (a) The liver receives as much as $25 \%$ of the blood volume that is pumped through the heart at any time unit; (b) The KCs and LSECs represent the surface that the blood encounters on its journey through the liver; (c) The total surface of the LSECs in the human liver facing the sinusoidal lumen is that of a tennis court [3]; (d) The ad- and ab-luminal surfaces of LSECs carry unique endocytosis receptors that recognize and internalize an array of blood-borne waste substances, including several nanoparticles as well as oligo- and polynucleotides [5-8]; (e) The endocytosis receptors in LSECs mediating blood clearance recycle back to the cell surface only seconds after they have delivered their cargo to the primary endosomes, making these receptors extremely efficient. Moreover, considering the effective intracellular transport toward lysosomes and their unusually high contents of lysosomal enzymes, there should be no surprise that the LSECs and KCs represent very active scavenger cells contributing importantly to the high blood clearance capacity of the liver.

Based on the remarkable scavenging activity of the LSECs and KCs, projects including development of large molecule compounds and nano-formulated therapeutics should include studies to determine (a) if the drug candidates accumulate preferentially in LSECs and/or KCs, (b) and if so, what receptors are involved in the recognition. Exact studies designed to determine to what extent any i.v. administered compound accumulates in the different types of liver cells require reliable methods to isolate pure preparations of LSECs, KCs, and HCs from a single liver. 
We pioneered the method of preparing LSECs, KCs, and HCs from a single rat liver, using collagenase perfusion to disperse the liver cells, followed by density separation on Percoll, and selective substrate adherence [9]. This method, which has been used with or without modifications by several laboratories, was later adapted by us for isolation and culture of mouse LSECs, KCs, and HCs [10].

While the procedure for isolation of HCs is rather straightforward and will be only briefly mentioned later in the present methods description, techniques for isolation of LSECs and KCs are more elaborate and will therefore be dealt with in greater detail in the present chapter. The great majority of the techniques used nowadays to generate initial single cell suspensions of liver include perfusion with a collagenase solution through the portal vein. The further steps comprise either centrifugal elutriation [11], Percoll density separation followed by selective adherence [10], or magnetic-activated cell sorting (MACS). Fluorescence-activated cell sorting (FACS) is frequently used to isolate KCs and LSECs. However, this method subjects the cells to considerable shear stress, which is probably why cell cultivation and functional studies of LSECs and KCs purified by FACS have been so scantly described in the literature. It has been reported that FACS of murine liver cells to produce LSECs resulted in a higher purity compared to MACS but was associated with a lower yield and recovery rate [12]. See [13] for a systematic review on methods for isolation and purification of murine LSECs. What is clear is that the cell yield, viability, and purity are affected by several steps in the cell isolation procedure, including the enzyme and technique used to disperse the liver cells, buffers, centrifugation steps, and antibody used for sorting. In rat, highly pure LSECs are reported with MACS isolation [14, 15] using the LSEC-specific antibody SE-1 [16], which targets the FcyRIIb2 in these cells [17].

We here describe the MACS procedure that we have developed for isolation of mouse KCs and LSECs, using F4/80 and CD146 as cell markers, which allows simultaneous isolation of highly pure HCs, LSECs, and KCs. The method is reliable because specific antibodies are commercially available for recognition of either KCs or LSECs in a suspension of mixed liver cells. Moreover, the procedure is fast and reproducible, and gives good cell yields. In addition, the MACS isolation procedure requires equipment that is considerably less expensive and easier to operate than elutriation centrifuges or flow cytometry cell sorters. During the isolation procedure, the cells and buffers are kept cold to minimize intracellular metabolic processes. After the final isolation step the cells can be seeded in culture dishes and maintained for functional studies or pelleted and used for further analysis. This allows for both in vivo liver cell distribution of intravascularly administered compounds, as well as in vitro analysis of how compounds interact with isolated cultures of KCs, LSECs, and HCs. 


\section{Materials}

\subsection{Perfusion}

System (Fig. 1)
1. Water bath.

2. Heat exchanger with bubble trap.

3. Pump.

4. Silicone tubing (use tubes with small diameter to avoid formation of air bubbles) (see Notes $\mathbf{1}$ ).

5. Intravenous cannula 22G.

6. Magnifier.

2.2 Materials for Perfusion

1. Small styrofoam "bed" for the mouse + tissue paper rolled to form a pillow.

2. Good scissors, forceps, surgical dressing tweezers.

3. Fridge/ice box for buffers.

4. Perfusion buffer (see steps 1 and 2 in Subheading 2.3 for preparation).

5. Liberase ${ }^{\mathrm{TM}}$ Research Grade, rehydrated and aliquoted in $1 \mathrm{mg}$ batches according to the manufacturer's protocol, and kept frozen until perfusion starts.

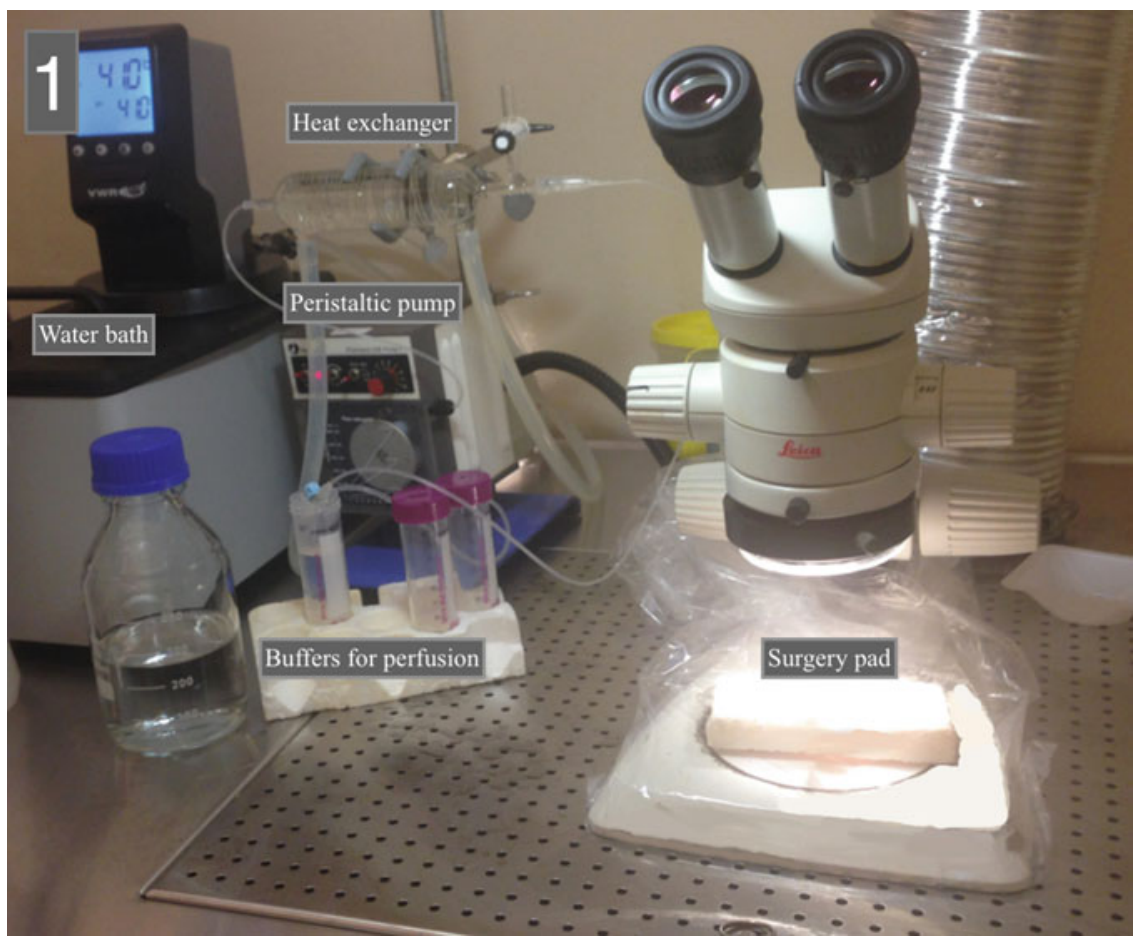

Fig. 1 Equipment for the perfusion system 
6. Liberase buffer (= perfusion buffer with $4.76 \mathrm{mM} \mathrm{CaCl}_{2}$, see steps 2 and 3 in Subheading 2.3) for dissolution of the defrosted Liberase ${ }^{\mathrm{TM}}$.

7. Cold AIM V medium (30 ml/mouse liver) for collection of cells after perfusion with Liberase ${ }^{\mathrm{TM}}$.

8. Petri dish $(10 \mathrm{~cm}$ diameter) for releasing cells from liver following perfusion with Liberase ${ }^{\mathrm{TM}}$.

9. The present protocol has been set up for C57BL/6 mice (see Note 2).

2.3 Buffers, Density Medium, Liberase ${ }^{\mathrm{TM}}$, Cell Culture Media, Coating of Cell Culture Dishes with

Fibronectin, MagneticActivated Cell Sorting (MACS) Isolation System (Hardware and Buffers)
1. Perfusion buffer: Dilute $40 \mathrm{ml}$ of perfusion buffer concentrate (see below) in milliQ sterile water to a total volume of 11 .

2. Perfusion buffer concentrate: Dissolve $103.75 \mathrm{~g} \mathrm{NaCl}, 6.25 \mathrm{~g}$ $\mathrm{KCl}$, and $28.70 \mathrm{~g}$ Hepes in $350 \mathrm{ml}$ milliQ $\mathrm{H}_{2} \mathrm{O}$ while stirring. When all has been dissolved add $75 \mathrm{ml}$ of $1 \mathrm{M} \mathrm{NaOH}$. Add $\mathrm{H}_{2} \mathrm{O}$ to a total volume of $500 \mathrm{ml}$. Filter (pore size $0.45 \mu \mathrm{m}$ ) the solution and distribute in tubes $(50 \mathrm{ml})$; freeze in portions of $40 \mathrm{ml}$. See [4] for more details on buffer compositions.

3. Liberase buffer: Add $0.5 \mathrm{ml}$ of $476 \mathrm{mM} \mathrm{CaCl}_{2}$ to $49.5 \mathrm{ml}$ of perfusion buffer to obtain a final concentration of $4.76 \mathrm{mM}$ $\mathrm{CaCl}_{2}$. Add $1.0 \mathrm{mg}$ of freshly defrosted stock of Liberase ${ }^{\mathrm{TM}}$ to give a working concentration of $0.02 \mathrm{mg} / \mathrm{ml}$ immediately before perfusion starts. See Note 3 regarding Liberase ${ }^{\mathrm{TM}}$ concentration.

4. Percoll (100\%): Mix $13.5 \mathrm{ml}$ stock Percoll ${ }^{\mathrm{TM}}$ with $1.5 \mathrm{ml} 10 \times$

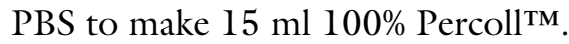

5. Medium for cultivation of HCs: Add 1 kit of Gibco ${ }^{\text {TM }}$ Primary Hepatocyte Maintenance Supplements to 1 bottle $(500 \mathrm{ml})$ of Gibco $^{\text {TM }}$ William's E Medium, no phenol red to prepare medium for culture of HCs.

6. Medium for cultivation of LSECs and KCs: Gibco ${ }^{\mathrm{TM}}$ AIM V VM Medium, liquid.

7. Coating of cell culture dishes with fibronectin for cultivation of LSECs and HCs: Use fibronectin prepared from bovine plasma ( $1 \mathrm{mg} / \mathrm{ml}$ ) to coat culture dishes at a concentration of $1-5 \mu \mathrm{g} /$ $\mathrm{cm}^{2}$. Coat culture surface with a minimal volume, just enough to cover the surface. Leave for $10 \mathrm{~min}$ at room temperature. Once the entire area is covered, remove excess solution, which can be reused to coat another well/plate. Leave for $10 \mathrm{~min}$ at room temperature. Wash $3 \times$ with PBS and let stand in PBS in the incubator until seeding of cells. PBS must be removed before cells are added.

8. MACS isolation system: CD146 MicroBeads (Miltenyi); antiF4/80 MicroBeads (Miltenyi); LS Columns (Miltenyi); QuadroMACS ${ }^{\mathrm{TM}}$ Separator (Miltenyi). 
9. Prepare MACS buffer: Mix autoMACS Rinsing Solution (Miltenyi) and MACS BSA Stock Solution (Miltenyi) according to instructions by the manufacturer.

3 Methods

\subsection{Preparing the Perfusion System}

If the aim is to study the distribution of an injected compound in the different types of liver cells, the compound must be injected before starting at Subheading 3.1. The time from injection of compound until the animal is euthanized, and the liver perfusion and cell isolation procedure start depends on the anticipated rate of metabolism of the injected compound. The faster the metabolism, the faster is the disappearance of the compound from the liver cells, and accordingly, the shorter should the time be from compound injection to cell isolation.

If the aim is to study interaction of compound with isolated liver cells, without prior intravenous administration, start directly at Subheading 3.1.

1. Heat perfusion buffer to approx. $70{ }^{\circ} \mathrm{C}$, and let it cool down. This operation drives air of the perfusion buffer, lowering the risk of bubble formation during the perfusion.

2. Wash the system with $10 \mathrm{ml}$ perfusion buffer ( see Note $\mathbf{1}$ ).

3. Allow the water bath to attain the correct working temperature (see Note 4).

4. Make sure there are no bubbles in the system (see Note $\mathbf{1}$ ).

5. Flow rate before starting the liver perfusion: approx. $9 \mathrm{ml} / \mathrm{min}$.

6. Make sure there is at least $50 \mathrm{ml}$ perfusion buffer in the tube before starting the liver perfusion.

7. Shortly before starting the liver perfusion, rapidly defrost Liberase $^{\mathrm{TM}}$, add it to the Liberase buffer and mix.

1. The entire procedure is carried out postmortem and must be started immediately after the animal has been euthanized according to the protocol of the ethical review permission that covers the research. The mouse images shown in Figs. 2, $3,4,5,6$, and 7 are from an in vitro experiment (euthanasia before sampling), and the experimental protocol and animal handling were approved by the competent institutional authority at UiT The Arctic University of Norway, which is licensed by the National Animal Research Authority at the Norwegian Food Safety Authority (Mattilsynet; Approval ID: UiT $02 / 20$ ), and experiments were performed in compliance with the European Convention for the protection of Vertebrate Animals used for Experimental and Other Scientific Purposes. 


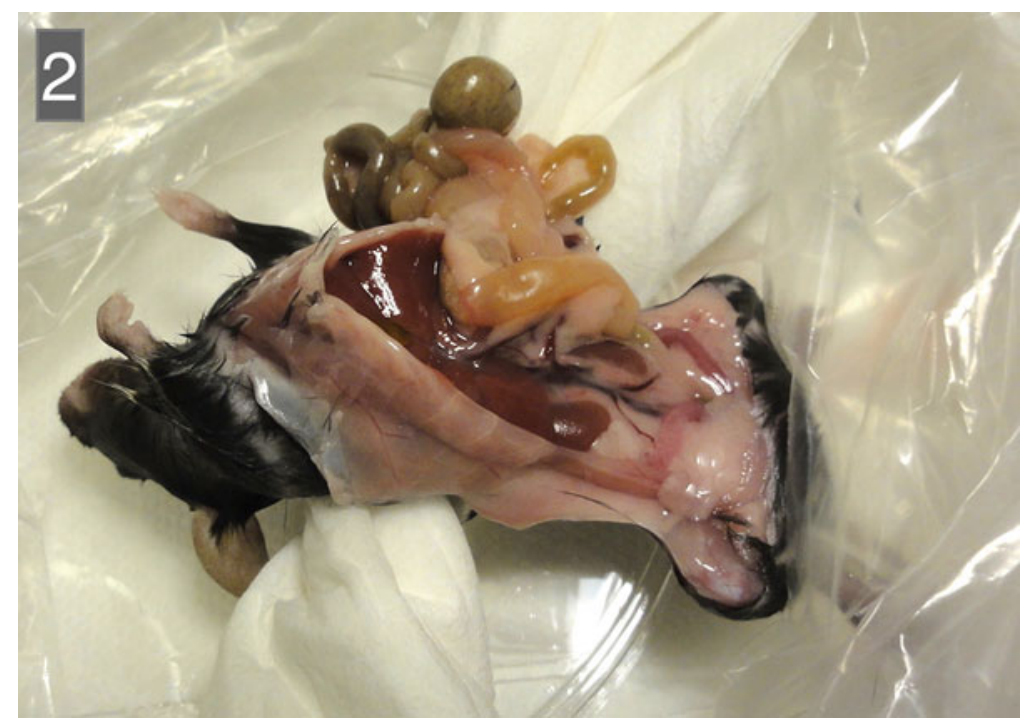

Fig. 2 Position of the mouse organs

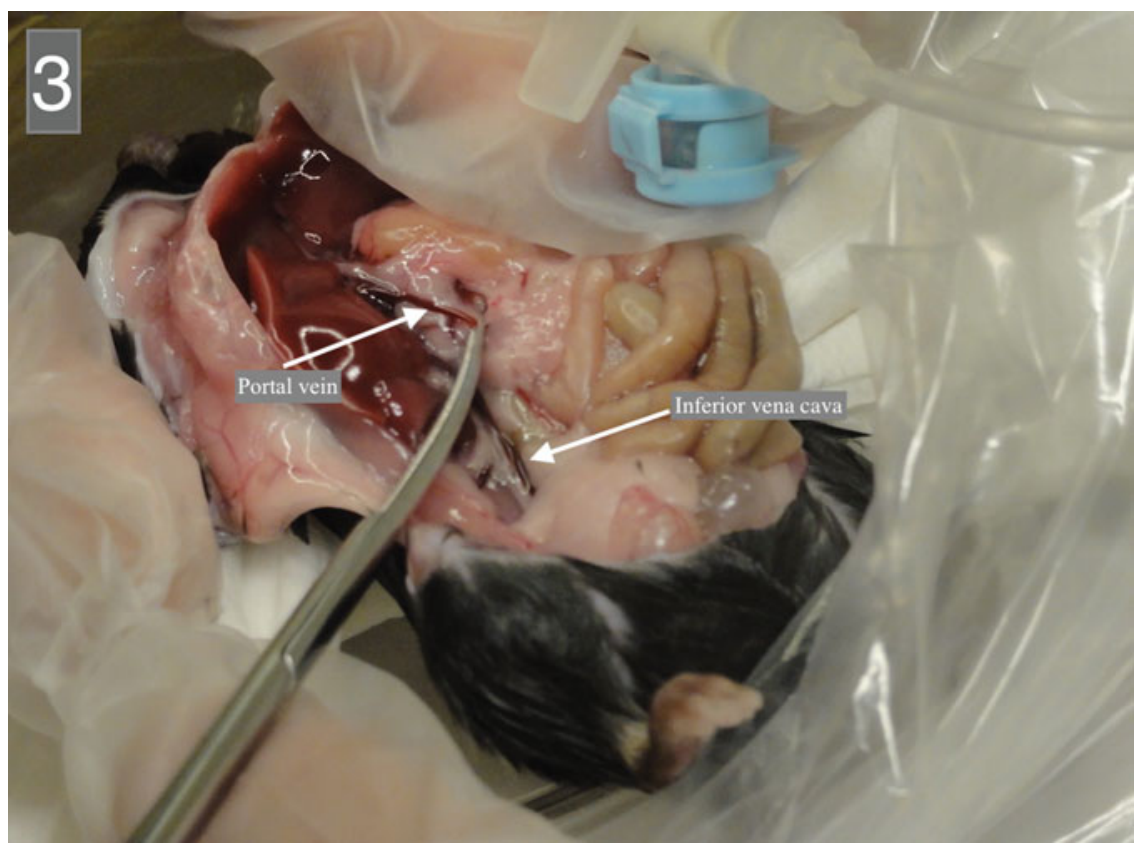

Fig. 3 Position of the portal vein and inferior vena cava

2. Place the animal on the bed with the tissue paper pillow under the abdomen, to position the liver at a slightly higher level than the rest of the organs.

3. Carefully open the abdomen by midline incision, making sure not to injure the liver. The abdominal cavity has to be well exposed for better visualization and access (Fig. 2). 


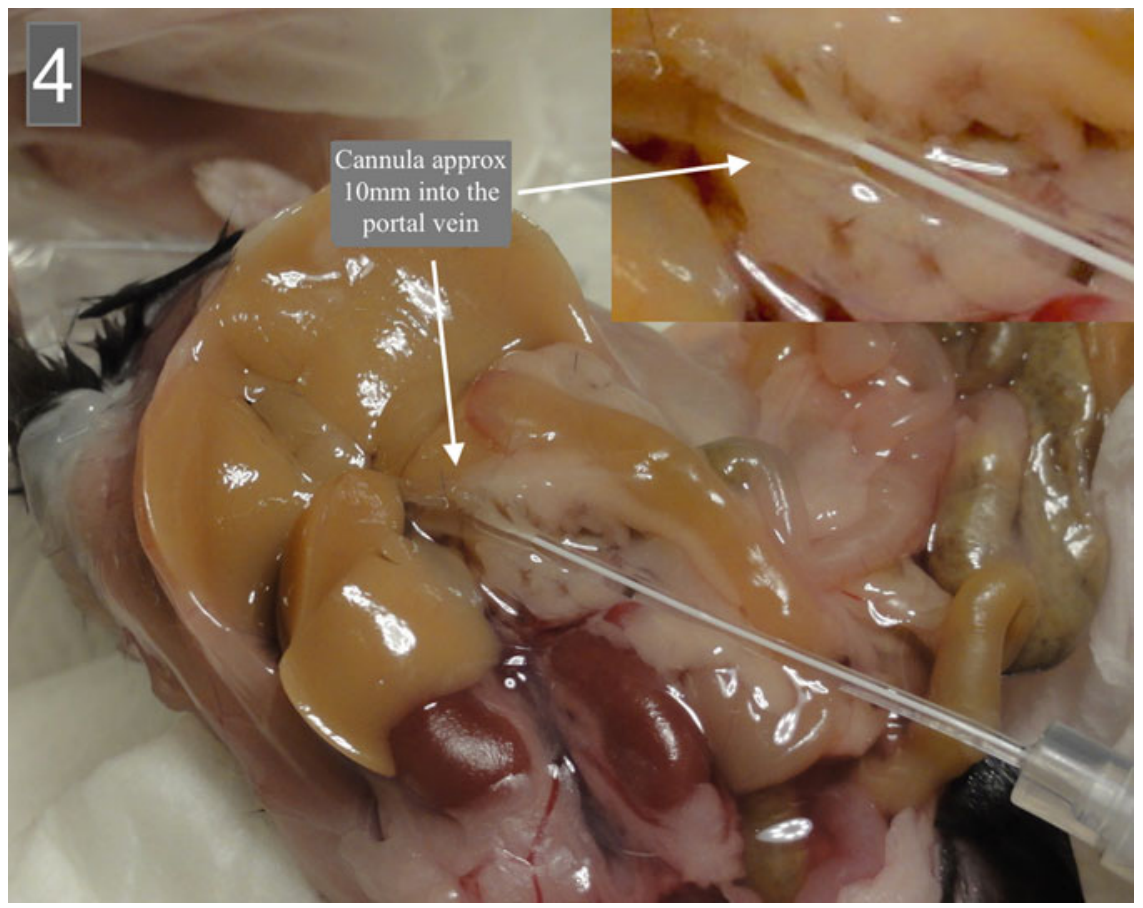

Fig. 4 Position of the canula in the portal vein

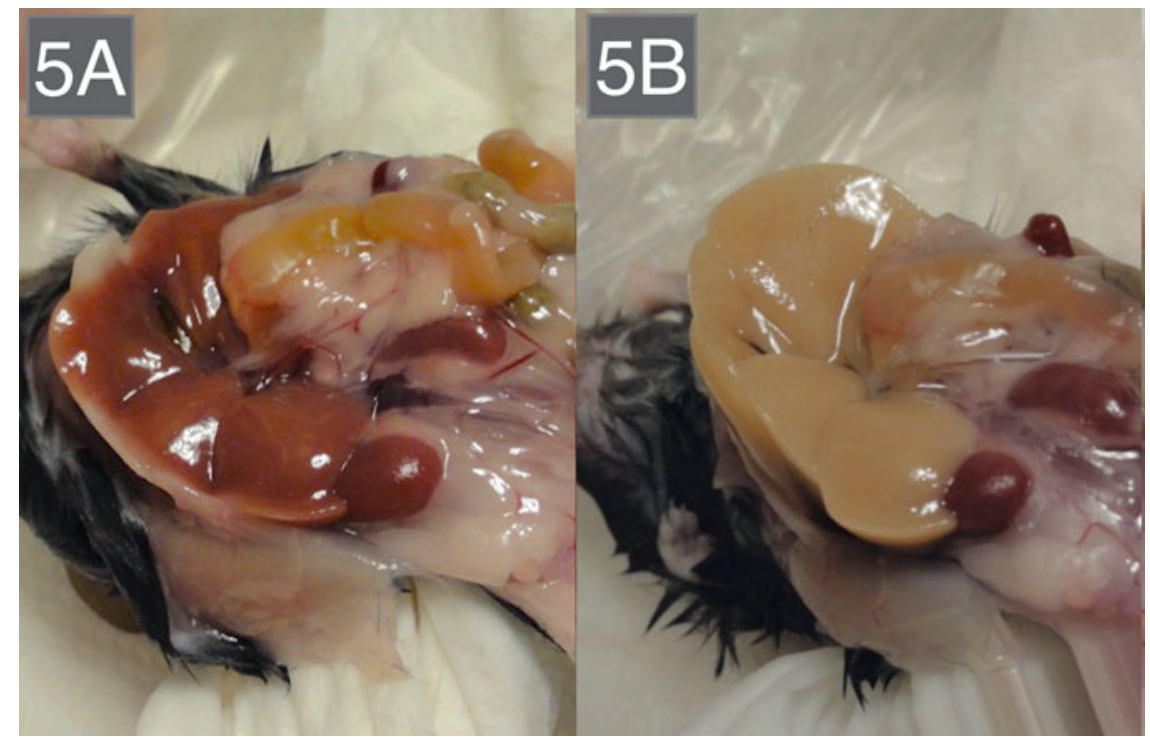

Fig. 5 Color shift of the organs 


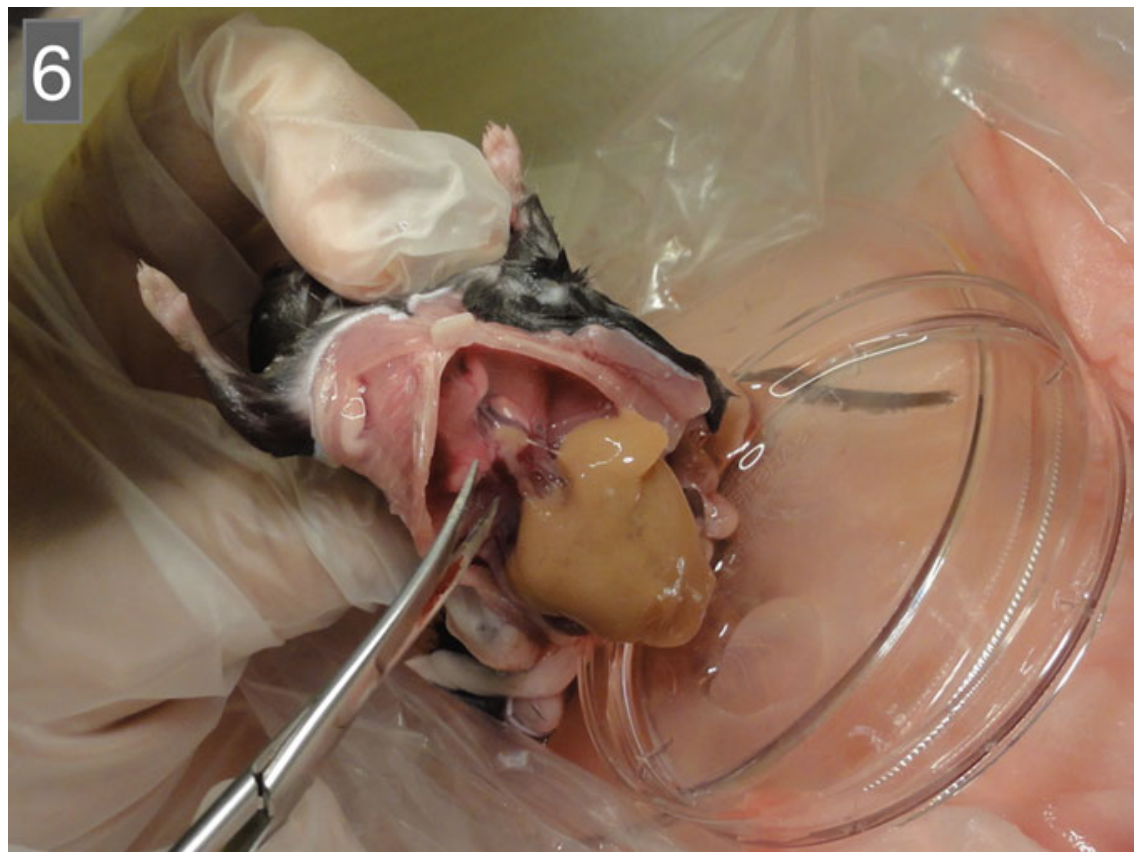

Fig. 6 Removal of the liver

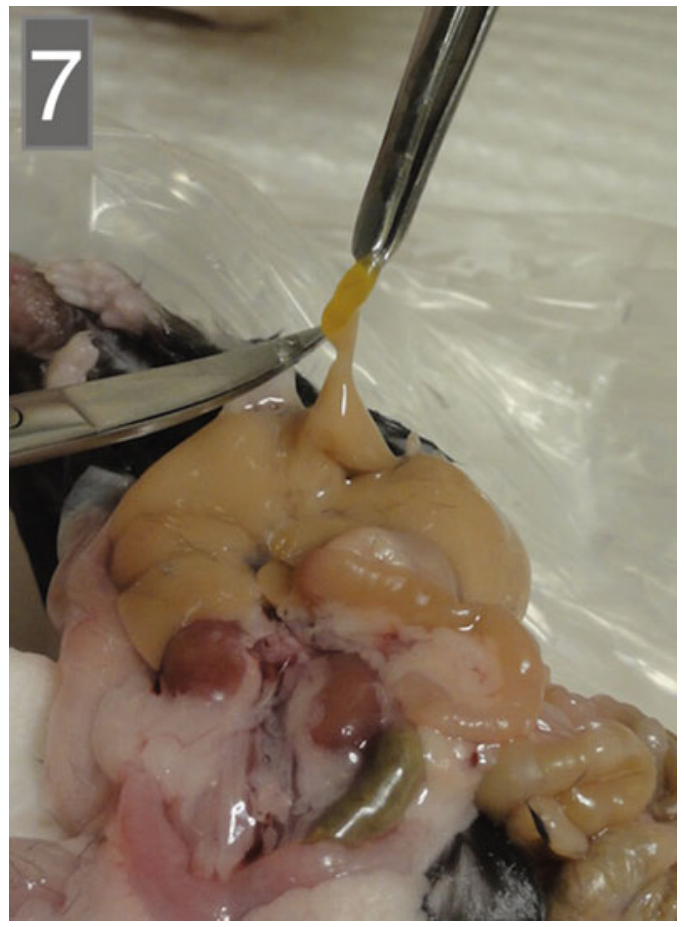

Fig. 7 Removal of the gall bladder 
4. Move the intestines to the side to expose the portal vein (Fig. 3).

5. Before reducing the flow rate to $4 \mathrm{ml} / \mathrm{min}$ flick the tubing all the way from the heat exchanger to the tubing tip to get rid of all visible air bubbles ( see Note $\mathbf{1}$ ).

6. Reduce the flow rate to $4 \mathrm{ml} / \mathrm{min}$ (make sure that there is a surplus of perfusion buffer in the $50 \mathrm{ml}$ tube in case more time is needed for the operation). Note that it is important to maintain this low flow rate during the insertion of the tubing cannula. Never stop the flow rate completely during any step of the operation.

7. Focus the magnifier on the portal vein and make a small incision (approx. 1/3 of the vein diameter). Do not cut the portal vein completely, as this will make it very difficult to insert the cannula. The incision should be made close to where the splenic vein enters the portal vein. In this way one ensures that the distance from the incision to the point where the portal vein enters the liver is sufficient to give the cannula a stable position, and at the same time the tip of the cannula will rest in a position that allows the perfusion of all liver lobes (Fig. 4).

8. Insert the cannula, by carefully moving it through the incision of the portal vein, in a movement nearly parallel to the vessel. In this way the cannula will slide smoothly in, and the risk of rupturing the vessel wall is minimized. A certain sign that the cannula has entered the vein is a rapid color shift of the liver from dark red (Fig. 5a) to yellow (Fig. 5b).

9. Cut the inferior vena cava as indicated with the arrow in Fig. 3 to allow the perfusion buffer to flow freely through the liver.

10. Increase the flow rate to $7-10 \mathrm{ml} / \mathrm{min}$ depending on the animal weight.

11. Keep on perfusing the liver with perfusion buffer to make sure no more blood is left (normally $10-20 \mathrm{ml}$ ).

12. Change to the Liberase buffer. Avoid entrance of air bubbles into the portal vein during this operation ( see Note $\mathbf{1}$ ).

13. When the liver cells are well dissociated by the perfusion with Liberase $^{\mathrm{TM}}$ (as judged by swelling, increased size and a softer appearance of the liver, pale color, and a tendency of Glisson's capsule to separate from the parenchyma), remove the cannula from the portal vein ( see Note $\mathbf{5}$ ).

14. Carefully remove the liver from the body, by cutting the ligaments using a small, sharp pair of scissors. Use the magnifier as a guide to fine-tune the cutting of ligaments around the stomach. Avoid rupturing the esophagus or intestines (Fig. 6) (see Note 5).

15. Carefully remove the gall bladder (Fig. 7) (see Note 5). 
16. Place the liver in the petri dish (with $10 \mathrm{ml}$ cold AIM V) and remove Glisson's capsule (see Notes 5 and $\mathbf{6}$ ).

17. Shake the liver gently to release the cells that have been dissociated during the Liberase ${ }^{\mathrm{TM}}$ perfusion. When no more cells seem to be released, pour the cell suspension into a $50 \mathrm{ml}$ tube and ice-cold AIM V medium to approx. $40 \mathrm{ml}$ (see Note 5).

18. Keep the cell suspension at $4{ }^{\circ} \mathrm{C}$.

19. Repeat perfusion operation with a new mouse or end by washing the system with $50 \mathrm{ml}$ of sterile water, fill with $70 \%$ ethanol, and leave it until next liver perfusion.

20. Release the tubings from the pump.

\subsection{Cell Isolation}

1. Very gently mix the cell suspension.

2. Spin down the HCs by differential centrifugation $(35 \times g$ for 2 min at $4{ }^{\circ} \mathrm{C}$; max acceleration/deceleration). The resulting pellet is enriched in HCs, and the supernatant is enriched in KCs and LSECs.

3. Pipette the KC/LSEC-enriched supernatant to a new centrifuge tube and repeat the differential centrifugation $(35 \times g$ for 2 min at $4{ }^{\circ} \mathrm{C}$; max acceleration/deceleration) ( see Note 7).

4. To increase the yield of $\mathrm{KC} / \mathrm{LSECs}$ resuspend the $\mathrm{HC}$-enriched pellet in $40 \mathrm{ml}$ perfusion buffer and repeat the differential centrifugation at $35 \times g$ for $2 \min$ at $4{ }^{\circ} \mathrm{C}$; $\max$ acceleration/deceleration (see Note 7).

5. For isolation of HCs, resuspend the HC-enriched pellet from step 4 in $20 \mathrm{ml}$ William's E medium and continue at step 3 in Subheading 3.3 .3 (procedure for isolation and culture of HCs).

6. For isolation of $\mathrm{KC} / \mathrm{LSECs}$, collect the resulting supernatants from steps 3 and 4 in Subheading 3.3, and centrifuge $(300 \times \mathfrak{g}$ for $10 \mathrm{~min}$ at $4{ }^{\circ} \mathrm{C}$; $\max$ acceleration/deceleration). Small, light-colored pellets indicate that the content of HCs is low, and the procedure can continue at step 10 in Subheading 3.3. $\mathrm{Big}$, darker colored pellets indicate high content of HCs, and a density separation on Percoll is recommended to deplete HCs from KCs and LSECs: to do this, resuspend the pellet in $11 \mathrm{ml}$ MACS buffer and mix with $9 \mathrm{ml} \mathrm{100 \%} \mathrm{Percoll} \mathrm{to} \mathrm{make} \mathrm{a} 20 \mathrm{ml}$ mix of $45 \%$ Percoll solution and cells. Carefully add $8 \mathrm{ml}$ MACS buffer on top (see step 9 in Subheading 2.3).

7. Centrifuge the $45 \%$ Percoll gradient: $1350 \times g$ for $25 \mathrm{~min}$ at $4{ }^{\circ} \mathrm{C}$. Set acceleration/deceleration to 5 (on scale from 1 to 9 ).

8. By means of a $10 \mathrm{ml}$ pipette collect the HC-depleted $\mathrm{KCs}$ and LSECs (non-HCs) from the top of the $45 \%$ Percoll cushion and resuspend in $5 \mathrm{ml}$ MACS buffer. Count the cells. 
3.3.1 MACS Isolation of $K C s$ and LSECS

3.3.2 Culturing LSECS (Continue Here After Step

5 in Subheading 3.3.1)
9. Centrifuge $\left(300 \times g\right.$ for $10 \mathrm{~min}$ at $4{ }^{\circ} \mathrm{C}$; max acceleration/ deceleration).

10. Resuspend pellet in MACS buffer to make a cell number/ volume ratio of $5 \times 10^{6}$ non-HCs per $100 \mu \mathrm{l}$. (If you go directly from step 6 to step 10 in Subheading 3.3, first resuspend the non-HC pellet in $5 \mathrm{ml}$ MACS buffer, count the cells, and centrifuge at $300 \times g$ for $10 \mathrm{~min}$ at $4{ }^{\circ} \mathrm{C}$; max acceleration/ deceleration.)

1. Mix $2 / 3$ of the total volume of non-HCs with $20 \mu \mathrm{l}$ of antiF4/80 MicroBeads (for isolation of KCs). Mix the remaining $1 / 3$ with $20 \mu \mathrm{l}$ of anti-CD146 MicroBeads (for isolation of LSECs). Incubate both non-HC suspensions for $15 \mathrm{~min}$ at $4{ }^{\circ} \mathrm{C}$ in $5 \mathrm{ml}$ centrifuge tubes.

2. Fill each of the two $5 \mathrm{ml}$ tubes with MACS buffer and centrifuge $\left(300 \times g\right.$ for $10 \mathrm{~min}$ at $4{ }^{\circ} \mathrm{C}$; max acceleration/deceleration). Aspirate both supernatants completely.

3. Resuspend each of the two pellets in $0.5 \mathrm{ml}$ MACS buffer and apply to two LS columns for magnetic isolation according to the instructions given by the manufacturer.

4. Wash the column with $3 \times 3 \mathrm{ml}$ MACS buffer. Discard the flow-through.

5. Remove the column from the magnetic field and fill it with $5 \mathrm{ml}$ MACS buffer. Immediately flush out the magnetically labeled cells by firmly pushing the plunger into the column. Collect the eluted volumes in two $15 \mathrm{ml}$ centrifuge tubes-one tube for the cells incubated with anti-F4/80 MicroBeads, and the other for the cells incubated with anti-CD146 MicroBeads. Spin the tubes $\left(300 \times g\right.$ for $10 \mathrm{~min}$ at $4{ }^{\circ} \mathrm{C}$; $\max$ acceleration/deceleration), resuspend the resulting pellets in $1 \mathrm{ml}$ AIM V medium, and count the cells. See Note 8 for details regarding yield, purity, and viability of isolated KCs and LSECs.

6. At this point the KCs and LSECs may be analyzed for contents of drug administered prior to the liver perfusion procedure.

7. If cells are to be used for in vitro analysis of drug uptake and intracellular processing, they may be cultured according to the following procedure.

1. Seed $0.25 \times 10^{6} \mathrm{LSECs} / 200 \mu \mathrm{AIM} \mathrm{V}$ medium $/ \mathrm{cm}^{2}$ growth area in fibronectin-coated cell culture wells. Place in a humidified $\mathrm{CO}_{2}$ incubator at $5 \% \mathrm{O}_{2}$.

2. After 35 min carefully wash with PBS or medium.

3. The LSEC cultures are now ready for experiments. Characteristic morphology of cultured LSECs is shown in Fig. 8a, b. See Note 9 for details regarding purity of cultured LSECs. 

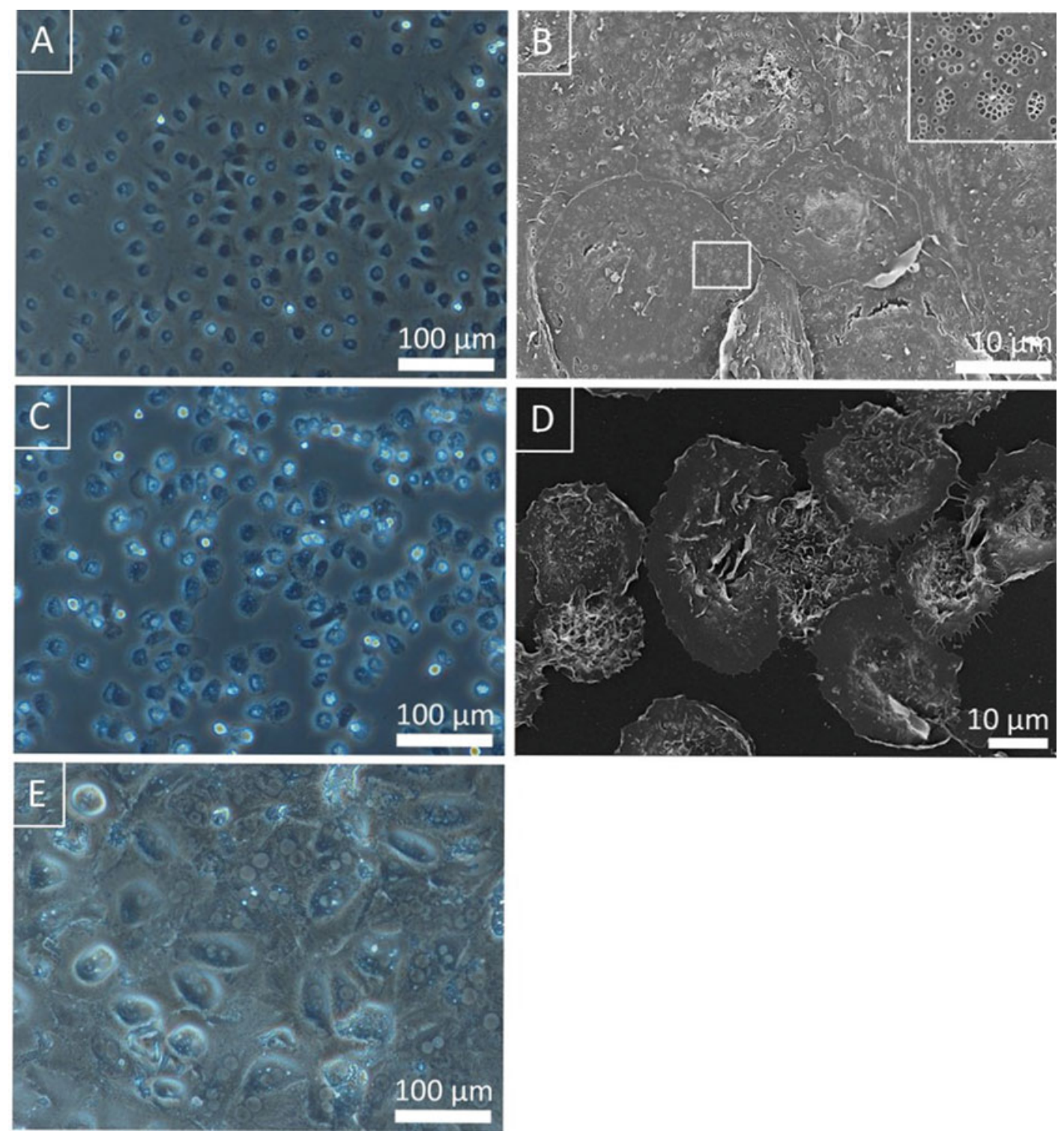

Fig. 8 Characteristics of the LSEC cultures. Phase contrast (a, c, e) and scanning electron micrographs (b, d) of mouse liver cells following isolation and culture. Liver cells were isolated as outlined in Subheading 3.3 and established in monolayer cultures. (a, b) LSECs $2 \mathrm{~h}$ following seeding. The inset in b shows typical LSEC fenestrations (open trans-cytoplasmic pores), which are a hallmark of these cells. (c, d) KCs $1 \mathrm{~h}$ following seeding. (e) HCs $48 \mathrm{~h}$ following seeding. LSECs and HCs were seeded on fibronectin-coated tissue culture plastic, and KCs were seeded on non-coated culture plastic. KCs and LSECs were cultured in AIM V medium, in $5 \% \mathrm{O}_{2}$ and $5 \% \mathrm{CO}_{2}$ atmosphere, whereas $\mathrm{HCs}$ were cultured in William's $\mathrm{E}$ medium with supplements, $5 \%$ fetal bovine serum, $0.1 \mu \mathrm{M}$ dexamethasone, and $20 \% \mathrm{O}_{2}$ and $5 \% \mathrm{CO}_{2}$. Following the indicated cultivation times the cultures for scanning electron microscopy were gently washed with medium prewarmed to $37^{\circ} \mathrm{C}$, fixed in McDowell's fixative for electron microscopy [18], and processed according to the protocol in [14], and examined in a Zeiss Sigma field emission scanning electron microscope, run at $2 \mathrm{kV}$. Phase contrast micrographs were taken with a $20 \times$ objective lens in a Nikon Eclipse TE300 inverted microscope, equipped with a Zeiss AxioCam MRc digital camera 
3.3.3 Culturing KCs (Continue Here After Step 5 in Subheading 3.3.1)

3.3.4 Isolation and Culturing of HCs (Continue Here After Step 4 in Subheading 3.3)
1. Seed $0.20 \times 10^{6} \mathrm{KCs} / 200 \mu \mathrm{l}$ AIM V medium $/ \mathrm{cm}^{2}$ growth area in non-coated cell culture wells. Place in a humidified $\mathrm{CO}_{2}$ incubator at $5 \% \mathrm{O}_{2}$.

2. After 35 min carefully wash with PBS or medium.

3 . The KCs are now ready for experiments. Characteristic morphology of cultured KCs is shown in Fig. 8c, d. See Note 10 for details regarding purity of cultured KCs.

1. Filter the resuspended HC-enriched pellet through a $70 \mu \mathrm{m}$ cell strainer to get rid of debris and cell aggregates that remain undissociated after the Liberase ${ }^{\mathrm{TM}}$ and centrifuge the filtrate $\left(54 \times g\right.$ for $2 \min$ at $4{ }^{\circ} \mathrm{C}$; $\max$ acceleration/deceleration).

2. Mix resulting pellet with $45 \%$ Percoll and centrifuge $(1350 \times g$ for $25 \mathrm{~min}$ at $4{ }^{\circ} \mathrm{C}$; set acceleration/deceleration to 5 on scale from 1 to 9 ).

3. After centrifugation remove the Percoll above the cell layer, fill up the tube with William's E medium, and mix with the remaining bottom layer of Percoll which contains the purified HCs. Spin down the HCs $\left(54 \times g\right.$ for $2 \min$ at $4{ }^{\circ} \mathrm{C}$; $\max$ acceleration/deceleration).

4. Resuspend in William's E medium and count the HCs. At this point the HCs may be analyzed for contents of drug if administered prior to the liver perfusion procedure. Determine viability, e.g., by the trypan blue exclusion test. See Note 11 for details regarding viability of HCs.

5. If the HCs are to be used for in vitro analysis of drug uptake and intracellular processing, they may be cultured according to the procedure described in steps 5-7 in Subheading 3.3.4.

6. Seed $0.15 \times 10^{6} \mathrm{HCs} / 200 \mu \mathrm{l}$ William's E medium with supplements (see step 5 in Subheading 2.3) and 5\% fetal bovine serum $/ \mathrm{cm}^{2}$ growth area in fibronectin-coated cell culture wells. Place in a humidified $\mathrm{CO}_{2}$ incubator at $20 \% \mathrm{O}_{2}$ (see Note 12).

7. After 4 h very carefully wash with William's E medium using a $1 \mathrm{ml}$ pipette. Continue cultivating the HCs in William's E medium with supplements (see step $\mathbf{5}$ in Subheading 2.3), with or without serum. See Note $\mathbf{1 3}$ regarding maintenance and serum requirement for $\mathrm{HC}$ cultures.

8. The HC cultures are now ready for experiments. Characteristic morphology of cultured HCs is shown in Fig. 8e. See Note 14 regarding purity of $\mathrm{HC}$ cultures. 
1. Great care must be taken to avoid the formation of air bubbles in the perfusion system, as trapping of air bubbles in the vascular system of the liver during perfusion will obstruct perfusion and greatly reduce the yield of cells.

2. The present protocol has been set up for C57BL/6 mice. Cell yields and time needed for cells to attach and spread optimally on growth substrates may vary between different mouse strains.

3. Although a concentration of $1 \mathrm{mg}$ Liberase ${ }^{\mathrm{TM}} / 50 \mathrm{ml}$ Liberase buffer $(0.02 \mathrm{mg} / \mathrm{ml}$ buffer $)$ is recommended to disperse liver cells from normal mouse liver, it is advisable to use a somewhat stronger concentration when cells are to be isolated from the liver of old mice or from mice with fibrotic liver. For these purposes the Liberase ${ }^{\mathrm{TM}}$ concentration may be increased to $0.03 \mathrm{mg} / \mathrm{ml}$, although it is recommended that tests be performed to establish the adequate concentration.

4. The working temperature of the water bath must be adjusted to give the buffer a temperature of $38^{\circ} \mathrm{C}$ at the tip of the cannula. (Tubing diameter, distance from heat exchanger, and flow rate affect the temperature drop along the tubing.)

5. For optimal viability, yield, and purity of isolated liver cells it is essential that the cells of the initial liver cell suspension following perfusion of the liver with Liberase ${ }^{\mathrm{TM}}$ are well dispersed as single cells, and with a minimum of aggregated cells and debris. A word of caution: if the liver is not satisfactorily transformed into a single cell suspension after the enzyme perfusion it is of little help to use mechanical force to tear the tissue apart, as this will result in massive formation of debris and dead cells. DNA leaking from dead cells will contribute to clumping of cells, and the result will be greatly reduced cell yield and viability.

6. It is not necessary to remove absolutely all of the Glisson's capsule; Glisson's capsule has to be ruptured and pulled off by means of tweezers to the extent that the dissociated liver cells can be gently shaken out into the buffer.

7. The purpose of the second differential centrifugation of the $\mathrm{KC} / \mathrm{LSEC}$-enriched supernatant is to remove more HCs which is important before the MACS isolation step, whereas the purpose of the second differential centrifugation of the resuspended HC pellet is to extract even more LSECs and KCs, which may still be present in the first HC pellet. The total yield of LSECs and KCs can be increased $20 \%$ by running a second differential centrifugation. Repeating this 
centrifugation step further will not give significantly increased yields of LSECs and KCs.

8. Yield, purity, and viability of isolated KCs and LSECs. With the method outlined here, using female C57BL/6 mice of 15-20 g body weight, and isolating all three cell types from the same liver we obtain $>95 \%$ pure preparations of KCs (yield: $2-4 \times 10^{6}$ cells per 3 mice) and LSECs (yield: $3-6 \times 10^{6}$ cells per 3 mice). Of note, the presently described method has been set up to isolate KCs and LSECs from $2 / 3$ and $1 / 3$ of the initial liver cell suspension. If more $\mathrm{KCs}$ are needed, the cell yield can be increase up to $3-6 \times 10^{6} \mathrm{KCs}$ per 3 mice by using the entire initial liver cell suspension. Similarly, the yield of LSECs can be increased up to $5-10 \times 10^{6}$ per mouse by using the entire initial liver cell suspension to make LSECs. Viability as judged by trypan blue exclusion is $\geq 95 \%$ for both KCs and LSECs.

9. Typical purity of cultured LSECs: 95-98\% (fenestrated cells assessed by scanning EM), with $\mathrm{KCs}$ as the dominating contaminating cell.

10. Typical purity of cultured KCs: Between $98 \%$ and $100 \%$.

11. Viability of HCs should be $>80 \%$. If viability is $<80 \%$ it is recommended that the cells be discarded. Viability routinely varies between $80 \%$ and $95 \%$.

12. HCs may be seeded in William's E medium with supplements ( see step 5 in Subheading 2.3) with or without 5\% fetal bovine serum and allowed to attach and spread on the growth substrate for $4 \mathrm{~h}$. Following washing the HC cultures may be continued by culturing in William's E medium with supplements (without serum see Subheading 2.3, step 5). HCs must be cultured in $20 \% \mathrm{O}_{2}$; they will not survive in $5 \% \mathrm{O}_{2}$.

13. Our experience is that $\mathrm{HC}$ cultures can be maintained up to at least $48 \mathrm{~h}$ without serum added to the medium.

14. Typical purity of cultured HCs: $>99 \%$.

\section{Acknowledgments}

The authors wish to acknowledge Prof. Karen Kristine Sørensen at UiT The Arctic University of Norway for assisting in proof reading of the manuscript, and also for providing light and electron microscopic images shown in Fig. 8. 


\section{References}

1. Godfrey C, Lourdes D, Smedsrød B, France P-R, Denti M, Disterer P, Lorain S, NogalesGadea G, Sardone V, Rayan A, EL-Andaloussi S, Lehto T, Khoo B, Hjortkjær C, van Roon-Mom W, Goyenvalle A, Aartsma-Rus A, ArechavalaGomeza V (2017) Delivery is key: lessons learnt from developing splice switching antisense therapies. EMBO Mol Med 9:545-557. https://doi.org/10.15252/emmm. 201607199

2. Setten RL, Rossi JJ, Han SP (2019) The current state and future directions of RNAi-based therapeutics. Nat Rev Drug Discov 18(6): 421-446. https://doi.org/10.1038/s41573019-0023-6

3. Sørensen KK, Smedsrød B (2020) The liver sinusoidal endothelial cell: basic biology and pathobiology. In: Arias IM, Alter HJ, Boyer JL, Cohen DE, Shafritz DA, Thorgeirsson SS, Wolkoff AW (eds) The liver: biology and pathobiology, 6th edn. Wiley, New York, pp 422-434

4. Pertoft H, Smedsrød B (1987) Separation and characterization of liver cells. In: Pretlow TGII, Pretlow TP (eds) Cell separation: methods and selected applications, vol 42. Academic Press, New York, pp 1-24. https://doi.org/10. 1016/B978-0-12-564504-1.50004-0

5. Sørensen KK, Simón-Santamaría J, McCuskey RS, Smedsrød B (2015) Liver sinusoidal endothelial cells. Compr Physiol 5:1751-1774. https://doi.org/10.1002/cphy.cl40078

6. Liu F, Shollenberger LM, Conwell CC, Yuan X, Huang L (2007) Mechanism of naked DNA clearance after intravenous injection. J Gene Med 9:613-619

7. Hisazumi J, Kobayashi N, Nishikawa M, Takakura Y (2004) Significant role of liver sinusoidal endothelial cells in hepatic uptake and degradation of naked plasmid DNA after intravenous injection. Pharm Res 21:1223-1228

8. Miller CM, Tanowitz M, Donner AJ, Prakash TP, Swayze EE, Harris EN, Seth PP (2018) Receptor-mediated uptake of phosphorothioate antisense oligonucleotides in different cell types of the liver. Nucleic Acids Ther 28: 119-127. https://doi.org/10.1089/nat. 2017.0709
9. Smedsrød B, Pertoft H (1985) Preparation of pure hepatocytes and reticuloendothelial cells in high yield from a single rat liver by means of Percoll centrifugation and selective adherence. J Leukoc Biol 38:213-230

10. Hansen B, Arteta B, Smedsrød B (2002) The physiological scavenger receptor function of hepatic sinusoidal endothelial and Kupffer cells is independent of scavenger receptor class A type I and II. Mol Cell Biochem 240:1-8

11. Knolle PA, Gerken G, Loser E, Dienes HP, Gantner F, Tiegs G, Meyer Zum Buschenfelde KH, Lohse AW (1996) Role of sinusoidal endothelial cells of the liver in concanavalin A-induced hepatic injury in mice. Hepatology 24:824-829

12. Bartneck M, Topuz F, Tag CG, Sauer-Lehnen$S$, Warzecha KT, Trautwein C, Weiskirchen R, Tacke F (2015) Molecular response of liver sinusoidal endothelial cells on hydrogels. Mater Sci Eng C Mater Biol Appl 51:64-72. https://doi.org/10.1016/j.msec.2015. 02.045

13. Meyer J, Gonelle-Gispert C, Morel P, Bühler L (2016) Methods for isolation and purification of murine liver sinusoidal endothelial cells: a systematic review. PLoS One 11:e0151945. https://doi.org/10.1371/journal.pone. 0151945

14. Bhandari S, Li R, Simón-Santamaría J, McCourt P, Johansen SD, Smedsrød B, Martinez- Zubiaurre I, Sørensen KK (2020) Transcriptome and proteome profiling reveal complementary scavenger and immune features of rat liver sinusoidal endothelial cells and liver macrophages. BMC Mol Cell Biol 21:85. https://doi.org/10.1186/s12860020-00331-9

15. Tokairin T, Nishikawa Y, Doi Y, Watanabe H, Yoshioka T, Su M et al (2002) A highly specific isolation of rat sinusoidal endothelial cells by the immunomagnetic bead method using SE-1 monoclonal antibody. J Hepatol 36(6): 725-733

16. Ohmura T, Enomoto K, Satoh H, Sawada N, Mori M (1993) Establishment of a novel monoclonal antibody, SE-1, which specifically reacts with rat hepatic sinusoidal endothelial 
cells. J Histochem Cytochem 4l(8): 1253-1257

17. March S, Hui EE, Underhill GH, Khetani S, Bhatia SN (2009) Microenvironmental regulation of the sinusoidal endothelial cell phenotype in vitro. Hepatology 50(3):920-928
18. McDowell EM, Trump BF (1976) Histologic fixatives suitable for diagnostic light and electron microscopy. Arch Pathol Lab Med 100: 405-414. https://pubmed.ncbi.nlm.nih.gov/ 60092/

Open Access This chapter is licensed under the terms of the Creative Commons Attribution 4.0 International License (http://creativecommons.org/licenses/by/4.0/), which permits use, sharing, adaptation, distribution and reproduction in any medium or format, as long as you give appropriate credit to the original author(s) and the source, provide a link to the Creative Commons license and indicate if changes were made.

The images or other third party material in this chapter are included in the chapter's Creative Commons license, unless indicated otherwise in a credit line to the material. If material is not included in the chapter's Creative Commons license and your intended use is not permitted by statutory regulation or exceeds the permitted use, you will need to obtain permission directly from the copyright holder. 